\section{Hitler - Scheitern und Vernichtungswut}

Gerhard Vinnai: Hitler - Scheitern und Vernichtungswut. Zur Genese des faschistischen Täters. Psychosozial-Verlag, Gießen 2004, ISBN: 3-89806-341-0, 24,90 Euro

m Klappentext heißt es, „Wie wurde Hitler zum Nationalsozialisten und zum Massenmörder?" Das herauszufinden, hatte sich der Autor zur Aufgabe gemacht.

Gerade das aber erfährt man in dem Buche nicht, oder nur auf antiquierte orthodoxanalytische Art. Man wundert sich, wie viele Erklärungsmöglichkeiten für einfache Sachverhalte dem Autor zur Verfügung stehen. Ein Beispiel von vielen: Vinnai untersucht den Werdegang Hitlers als Politiker und stellt u.a. dar, wie entscheidend Hitler durch traumatische Erfahrungen im Ersten Weltkrieg geprägt wurde: „Geschlagene Soldaten des Ersten Weltkriegs wollten einen siegreichen Zweiten Weltkrieg führen, der ihre Niederlage und damit auch die Traumatisierung durch diesen Krieg ungeschehen machen sollte ... Aber sie führten diesen Krieg so, dass er nur in einer erneuten Niederlage enden konnte..."Wieso das so sein soll, kann man nur schwer begreifen, denn es gab viele Soldaten des Ersten Weltkrieges, die ein und für alle Mal vom Krieg genug hatten, und es gibt viele Hinweise von Fachleuten, also der Historiker, das der Zweite Weltkrieg so einfach nicht zustande gekommen ist. Ein anderes Beispiel willkürlich herausgegriffen: Hitlers unbestreitbare Anhänglichkeit und Liebe zu seiner Mutter wird für eine Fülle von pathologischem Verhalten gebraucht. Dass die Mutter sich an ihn hängt und er der Mutter Liebe zurück gibt, wo $\mathrm{H}$. im wesentlichen mit seiner Mutter allein aufwuchs und der Vater ein damals üblich autoritäres Gewaltregime führte, muss für alles mögliche her halten, unter anderem auch für eine angeblich sexuelle Abartigkeit Hitlers. Alle Fakten und alle Berichte aber über Hitlers Sexualleben zeigen übereinstimmend, dass Hitler - wenn man so sagen darf - eine „stink normale“ Sexualität lebte. Auch beim besten Willen konnten Auffälligkeiten in diesem Zusammenhang keiner erkennen, der direkten Kontakt über viele Jahre zu Hitler hatte, wie seine engsten Mitarbeiter, Diener, Adjutanten, Sekretärinnen usw. Bei dem Hitler angedichteten Wahn „die Juden sind an allem schuld" handelt es sich nicht um einen Wahn in psychiatrischer Sichtweise, sondern um eine überwertige Idee. Antisemitismus hat es in der Zeit, in der Hitler diese überwertige Idee entwickelte, in Wien, einer Hochburg des Antisemitismus, häufig gegeben und Antisemitismus gehörte damals quasi zum guten Ton einer bestimmten Gesellschaftsschicht.

Im allgemeinen sind die groben Daten korrekt, allerdings ist der Autor wie viele anderen vor und nach ihm mit Einzelheiten nicht sicher vertraut. Beispielsweise wird immer wieder behauptet, dass Hitler mehr oder weniger armselig und mittellos in Wien herum irrte. Davon kann nebenbei bemerkt nicht die Rede sein.

Das Buch ist bemerkenswert in sich geschlossen und in seiner Theorie außerordentlich streng und konsequent ausgerichtet. Allerdings hätte für Hitler auch irgend eine andere Person herausgegriffen werden können. Man kann sagen, dass für angehende Fachleute, die sich für eine analytische Interpretation interessieren, dieses Buch als eine Art Lehrbuch darstellt, es gibt Anleitung dafür, wie aus dem Leben eines Einzelnen Sachverhalte gedeutet werden können, um einer Theorie zu genügen. Prof. F. Reimer, Weinsberg 